\title{
Investigating the Effect of In Ovo Injection of Silver Nanoparticles on Fat Uptake and Development in Broiler and Layer Hatchlings
}

\author{
Lane Pineda, ${ }^{1}$ André Chwalibog, ${ }^{1}$ Ewa Sawosz, ${ }^{2}$ Anna Hotowy, ${ }^{1}$ Jan Elnif, ${ }^{1}$ and Filip Sawosz ${ }^{1}$ \\ ${ }^{1}$ Department of Veterinary Clinical and Animal Sciences, University of Copenhagen, Groennegaardsvej 7, \\ 1870 Frederiksberg C, Denmark \\ ${ }^{2}$ Department of Animal Nutrition and Feed Science, Warsaw University of Life Sciences, Ciszewskiego 8, 02-786 Warsaw, Poland
}

Correspondence should be addressed to Lane Pineda, lane@sund.ku.dk

Received 9 March 2012; Accepted 3 September 2012

Academic Editor: Steven Li

Copyright (c) 2012 Lane Pineda et al. This is an open access article distributed under the Creative Commons Attribution License, which permits unrestricted use, distribution, and reproduction in any medium, provided the original work is properly cited.

\begin{abstract}
Silver nanoparticles (AgNano) as carrier of available oxygen $\left(\mathrm{O}_{2}\right)$ and with high surface reactivity may increase $\mathrm{O}_{2}$ consumption, enhance fat uptake (FU), and stimulate growth and development. The objective was to investigate the effects of in ovo injection of AgNano on the metabolic rate $\left(\mathrm{O}_{2}\right.$ consumption, $\mathrm{CO}_{2}$ production, and heat production, $\left.\mathrm{HP}\right)$, fat uptake, and the development of broiler and layer hatchlings. AgNano concentrations (50,75, and $100 \mathrm{mg} / \mathrm{kg}$ ) were injected in ovo at day 1 of incubation to different breeds of broiler and layer chicken embryos. Oxygen consumption and subsequently FU did not increase linearly following AgNano treatment. FU was lower in hatchlings treated with 50 and $100 \mathrm{mg} \mathrm{AgNano} / \mathrm{kg}$, but surprisingly not in hatchlings treated with $75 \mathrm{mg} \mathrm{AgNano} / \mathrm{kg}$. Interestingly, the difference in FU between treatments was not reflected in hatchling development. The results indicated that AgNano affected metabolic rate and FU; however, it did not influence the development of hatchlings. This suggests that in ovo injection of AgNano reduces the need to use yolk fat as an energy source during embryonic development and consequently the remaining fat in the residual yolk sac may provide a potent source of nutritional reserves for chicks of few days after hatching.
\end{abstract}

\section{Introduction}

During the latter part of incubation, fat in the yolk provides the main source of energy for the developing embryo. Glucose from carbohydrates and protein provides an important source of energy during the first two weeks of embryonic development, and from then until 2 or 3 days before internal piping, fatty acids from the yolk supply $90 \%$ of the energy requirement of the embryo. Towards the end of incubation, a few days before piping, energy metabolism switches to glucose through gluconeogenesis and glycogenesis [1-3].

Oxygen $\left(\mathrm{O}_{2}\right)$ is an important factor for the effective retrieval of fat and $\beta$-oxidation of fatty acids from the yolk $[1,2]$. In the developing embryo, starting at day 14 , the chorioallantoic membrane mediates the transfer of $\mathrm{O}_{2}$ between the pores of the shell and the embryo $[2,4]$. However, toward the end of incubation, $\mathrm{O}_{2}$ consumption reaches a plateau stage because of a restriction in the $\mathrm{O}_{2}$ diffusion capacity of the shell pore system. Consequently, the supply of $\mathrm{O}_{2}$ to the developing embryo becomes limited and the resultant hypoxia limits fat metabolism and eventually the growth of the embryo [5].

Several techniques are under investigation to mitigate this effect and facilitate growth before and after hatching. In ovo nutrient supply, for example, is a technique that involves the injection of a nutrient solution few days prior to piping to provide an external source of energy to the embryo and to the hatchlings $[3,6]$. The technique is very promising; however, the practice remains to be perfected and commercialised. Consequently, the development of other approaches needs to be considered.

Recently, we reported that the metabolism of layer embryos can be modified with the in ovo injection of silver nanoparticles (AgNano) [7]. We demonstrated that AgNano at a concentration of $50 \mathrm{mg} / \mathrm{kg}$, when injected in ovo at day 1 of incubation, increased the metabolic rate in layer embryos. However, in the previous experiment, this improvement in metabolic rate did not improve the growth of embryos. 
Therefore, the effect of different concentrations of AgNano was conducted via a dose-response experiment. This was to determine the optimum effective concentration of AgNano that will increase metabolic rate as well as improving the growth and development of broiler and layer chicken hatchlings. The study was extended to the determination of fat uptake in newly hatched chicks, considering that, in addition to genetic background; one factor for the growth difference between broiler and layer embryos is the rate of fat utilisation $[8,9]$. Also, under practical conditions, hatchlings rely mainly on residual yolk sac components as an immediate source of nutrition for a few days after hatching until they receive an external source of nutrients [10]. We hypothesised that the introduction of AgNano capable of carrying $\mathrm{O}_{2}$ at the cellular level would offer an alternative approach in providing the $\mathrm{O}_{2}$ requirements of the developing embryo. Due to the high surface reactivity of AgNano, this treatment may promote the oxidation of fat in the yolk and subsequently fat uptake in hatchlings. The objectives of the study were to determine the effect of in ovo injection of AgNano on the metabolic rate (oxygen consumption, $\mathrm{O}_{2}$; carbon dioxide production, $\mathrm{CO}_{2}$; heat production), fat uptake, and the development of broiler and layer hatchlings.

\section{Materials and Methods}

2.1. Experimental Design. A $2 \times 3$ factorial experiment with two breeder strains (Ross $\times$ Ross 308 and Lohmann) and three AgNano concentrations (50, 75 and $100 \mathrm{mg} / \mathrm{kg}$ ) was used.

584 fertile chicken eggs from Lohmann (layer-type) and Ross $\times$ Ross 308 (broiler-type) breeder strains of the same age (37 weeks old) were obtained from a commercial hatchery. In each breeder strain, 292 eggs were randomly grouped into two batches and stored in a refrigerator $\left(10^{\circ} \mathrm{C}\right)$ for $1-3$ days before being placed in the incubator. In each batch, 140 eggs were distributed into 5 treatment groups, with 28 eggs per treatment from which 12 eggs from each treatment were used for the measurement of $\mathrm{O}_{2}$ consumption and $\mathrm{CO}_{2}$ production, 5 eggs for the evaluation of hatchling development, and the rest were used as reserves. In addition, 12 eggs per breeder strain were opened at day 1 and the yolk samples were collected. At day 1 of incubation, the eggs from the first batch were numbered and injected according to the following treatment descriptions: (1) control (no injection), (2) sham control (placebo), (3) $50 \mathrm{mg} \mathrm{AgNano/kg,} \mathrm{(4)} 75 \mathrm{mg} \mathrm{AgNano} / \mathrm{kg}$, and (5) $100 \mathrm{mg} A g N a n o / k g$. The eggs were injected with 0.3 $\mathrm{mL}$ of a hydrocolloidal AgNano and phosphate buffered saline solution (placebo) into the air sac using a sterile 27 gauge, $20 \mathrm{~mm}$ needle. Immediately after injection, the hole was sealed with hypoallergenic tape and the eggs were placed into an incubator. The eggs were incubated for 21 days under standard conditions (temperature $37.8^{\circ} \mathrm{C}, 55 \%$ humidity, eggs turned once per hour for the first 18 days, and temperature $37^{\circ} \mathrm{C}$, and $60 \%$ humidity from day 19 until hatching). The same procedure was repeated for the eggs in batch 2 on the following day.
2.2. Gas Exchange Measurement. The $\mathrm{O}_{2}$ consumption and $\mathrm{CO}_{2}$ production were measured at day $10,13,16$, and 19 of incubation, according to the procedure described by Chwalibog et al. [11]. Gas exchange measurement was based on the paramagnetic principle in an open air circuit respiration unit (Micro-Oxymax calorimeter from Columbus Instruments, Columbus, OH, USA), equipped with four respiration chambers with a volume of $2000 \mathrm{~cm}^{3}$. The concentrations of $\mathrm{O}_{2}$ and $\mathrm{CO}_{2}$ in the incoming atmospheric air to the chambers were $20.946 \%$ and $0.038 \%$, respectively. The temperature and relative humidity were kept similar to that in the incubator.

The eggs were weighed and candled prior to measurements to check for the presence of embryos. Eggs without an embryo were discarded and replaced with eggs of the same age from the same treatment kept in the incubator as reserves. Six eggs from each treatment were placed in the respiration chambers and measured for $3 \mathrm{~h}$ from 9:00 to $12: 00$, followed by another six eggs from the same treatment measured from 13:00 to 16:00. After each measurement, the eggs were put back into the incubator. The procedure was repeated over the following day with the other batch of eggs; thus, a total of 24 eggs were measured from each treatment per breeder strain. All gas exchange and heat production (HP) measurements were standardised to a $50 \mathrm{~g}$ egg mass in order to account for differences in weight during each measurement.

$\mathrm{HP}$ was calculated from $\mathrm{O}_{2}$ consumption and $\mathrm{CO}_{2}$ production in accordance with Brouwer [12]: $\mathrm{HP}, \mathrm{kJ}=$ $16.18 \times \mathrm{O}_{2}, \mathrm{~mL}+5.02 \times \mathrm{CO}_{2}, \mathrm{~mL}$.

2.3. Nanosolution. Hydrocolloid AgNano solutions were obtained from Nano-Tech (Warsaw, Poland) and were produced by a patented nonexplosive high voltage method (Polish Patent 3883399) from high purity metals (99.9999\%) and high purity demineralised water. The concentrations of nanoparticles in the hydrocolloids were 50, 75, and $100 \mathrm{mg} / \mathrm{kg}$ AgNano with a particle size ranging from 2 to $35 \mathrm{~nm}$ based on TEM evaluations as described by Chwalibog et al. [13].

2.4. Yolk and Yolk Sac Sampling. All eggs were weighed at day 1 of incubation to determine the egg weight at setting. Twelve eggs from each breeder strain, representing the average weight of the eggs at set, were selected at day 1 for fresh yolk collection. At $24 \mathrm{~h}$ after hatching, 10 chicks from each treatment were euthanised by decapitation and the yolk sac (YS) was removed from the abdominal cavity and then weighed, stored at $-20^{\circ} \mathrm{C}$ and freeze-dried prior to analysis.

2.5. Hatchling Measurement. On the day of hatching, newly hatched chicks were kept without feed and water in a temperature-controlled $\left(32^{\circ} \mathrm{C}\right)$ brooder box furnished with a heat lamp for $24 \mathrm{~h}$. Chick weight (CW; $n=10)$ was measured; thereafter, they were euthanized and the liver, heart, and intestine were dissected and weighed.

The experimental procedures followed Danish National Legislation. 
2.6. Analyses. Yolk samples collected at day $1(n=12)$ and residual YS at $24 \mathrm{~h}(n=10)$ after hatching were analysed in triplicate for the contents of DM and fat. The DM content of wet and freeze-dried yolk was analysed by drying in an oven at $105^{\circ} \mathrm{C}$ overnight while the fat content was determined using a freeze-dried sample by petroleum ether extraction in a Soxtec system after $\mathrm{HCl}$ hydrolysis. The nitrogen $(\mathrm{N})$ content was not considered for analysis because $\mathrm{N}$ in yolk could not be determined accurately due to infiltration of protein and water from the nonyolk egg compartments, as reported by Yadgary et al. [10].

2.7. Calculations. Yolk-free body weight (YFBW) was determined as the difference between CW and the residual YS. Liver, heart, and intestine weights relative to YFBW (as \% of YFBW) were used to calculate relative organ weights ( $\mathrm{g}$ of organ weight/g of YFBW $\times 100$. The absolute weights of the YS, yolk fat content (YF), and fat uptake (FU) and their weights relative to YFBW (as \% of YFBW) were both calculated, and in case the trend is the same, only the absolute values are shown.

$\mathrm{YF}$ at day $1\left(\mathrm{YF}_{\mathrm{d} 1}\right)$ was determined by multiplying the concentration of fat in the yolk with the weight of yolk at day $1 . \mathrm{YF}$ at $24 \mathrm{~h}$ after hatching $\left(\mathrm{YF}_{24 \mathrm{~h}}\right)$ was calculated by multiplying the concentration of fat in the YS with the weight of the residual YS $24 \mathrm{~h}$ after hatching. FU was determined by calculating the difference in fat contents between the two time points $\left(\mathrm{FU}=\mathrm{YF}_{\mathrm{d} 1}-\mathrm{YF}_{24 \mathrm{~h}}\right)$.

2.8. Statistical Analysis. Data were analysed using the GLM procedure of SAS (SAS Institute Inc., 2009) considering the main effects of treatments (50, 75, and $100 \mathrm{mg} / \mathrm{kg}$ AgNano), breeder strain (Ross or Lohmann), and the interactions between these variables. The Tukey-Kramer honestly significant difference test was used to test the separation of the means at a significance level of $P<0.05$. Data from the placebo group were omitted from analysis due to a technical problem that caused the death of the embryos in this group.

\section{Results}

3.1. Yolk Sac Weight, Fat Content, and Fat Uptake. The residual YS weight was larger in hatchlings treated with AgNano $(P=0.001$; Figure $1(\mathrm{a}))$. At $24 \mathrm{~h}$ after hatching, no differences were observed among the AgNano concentrations; however, compared with the control, hatchlings treated with 50 and $100 \mathrm{mg}$ AgNano/kg had larger residual YS. The YS weight of hatchlings treated with $75 \mathrm{mg}$ AgNano/kg was intermediate.

The residual YS of hatchlings treated with $100 \mathrm{mg}$ AgNano $/ \mathrm{kg}$ contained more fat $(P<0.0001$; Figure 1(b)) compared with the hatchlings treated with $75 \mathrm{mg} \mathrm{AgNano} / \mathrm{kg}$ and the control (no injection) group, but was not different from the hatchlings treated with $50 \mathrm{mg}$ AgNano/kg, which had a comparable YF with all treatments. The $\mathrm{FU}$ of hatchlings treated with 50 and $100 \mathrm{mg}$ AgNano/kg was the same, but it was lower compared with the hatchlings in the control (no injection) group
$(P<0.0001$; Figure 1(c)). The FU of hatchlings treated with $75 \mathrm{mg}$ AgNano/kg was comparable with the FU of hatchlings treated with $50 \mathrm{mg} \mathrm{AgNano} / \mathrm{kg}$ and control, but it was higher than the hatchlings treated with $100 \mathrm{mg} \mathrm{AgNano} / \mathrm{kg}$ $(P<0.0001$; Figure 1(c) ).

Fresh yolk weight (18.6 versus $15.8 \mathrm{~g}$ ) was larger in broiler eggs at day 1 of incubation compared with layer eggs. Expectedly, the YF content (5.97 versus $4.82 \mathrm{~g}$ ) was also higher in broiler than in layer eggs. The weight of residual YS was $0.37 \mathrm{~g}$ higher $(P<0.0001$; Figure $2(\mathrm{a}))$ and the amount of YF was $0.59 \mathrm{~g}$ higher $(P<0.0001$; Figure $2(\mathrm{~b}))$ in broiler than in layer hatchlings. The $\mathrm{FU}$ was $0.4 \mathrm{~g}$ higher in broiler compared with layer hatchlings $(P<0.0001$; Figure $2(\mathrm{c}))$.

There was no significant interaction effect between treatment and breeder strain on the YS, YF, and FU (data not shown).

3.2. Chick Weight and Organ Weights. AgNano concentrations did not affect egg weight at setting $(60.7 \pm 0.33)$, YFBW or the relative weights of the intestine, heart, and liver (\% of YFBW) compared with the control (all $P>0.05$; data not shown).

The weight of eggs at setting was $5 \%$ heavier in broilers than in layers (63.0 versus 60.0; $P<0.0001$ ). The YFBW of broiler hatchlings was $13 \%$ heavier than in layer hatchlings $(P<0.0001$; Figure 2(d)). Except for the relative weight of the intestine, no effect was noted on other organ weights. The relative weight of the intestine in broilers was $8 \%$ heavier than in layer hatchlings (5.0 versus $4.6 \%$; $P<0.0001$ ). The relative heart and liver weights did not differ between breeder strains $(P>0.05$; data not shown).

No interaction effect was noted between treatment and breeder strain on YFBW and the relative weights of intestine, liver, and heart $(P>0.05$; data not shown).

3.3. Metabolic Rate. An effect of treatment and breeder strain was observed on gas exchange and HP. The hatchlings treated with 50 and $100 \mathrm{mg} \mathrm{AgNano} / \mathrm{kg}$ had the lowest metabolic rate $\left(\mathrm{O}_{2}\right.$ consumption, $\mathrm{CO}_{2}$ production, and $\left.\mathrm{HP}\right)$ during incubation $(P<0.001$; Table 1$)$.

Broiler embryos consumed $13 \%$ more $\mathrm{O}_{2}$, produced $17 \%$ more $\mathrm{CO}_{2}$, and expended $14 \%$ more heat compared with layer embryos $(P<0.001$; Table 1$)$.

There was no interaction effect recorded between treatment and breeder strain on the metabolic rate $(P>0.05$; data not shown).

\section{Discussion}

4.1. Fat Uptake. This study revealed that AgNano reduced $\mathrm{FU}$, indicating a reduction in fat oxidation, as demonstrated by higher weights of the YS and YF $24 \mathrm{~h}$ after hatching. The results are unexpected and contrary to our hypothesis that AgNano, as carrier of available $\mathrm{O}_{2}$ with high surface reactivity, would increase $\mathrm{O}_{2}$ consumption and accelerate fat oxidation. In the current study, we demonstrated that $\mathrm{FU}$ was lower in hatchlings treated with 50 and $100 \mathrm{mg} \mathrm{AgNano} / \mathrm{kg}$, but surprisingly not in hatchlings treated 


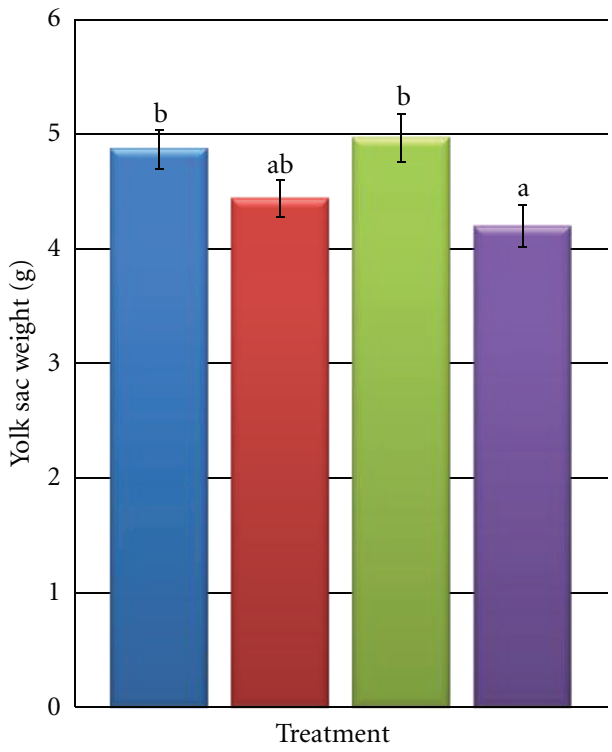

(a)

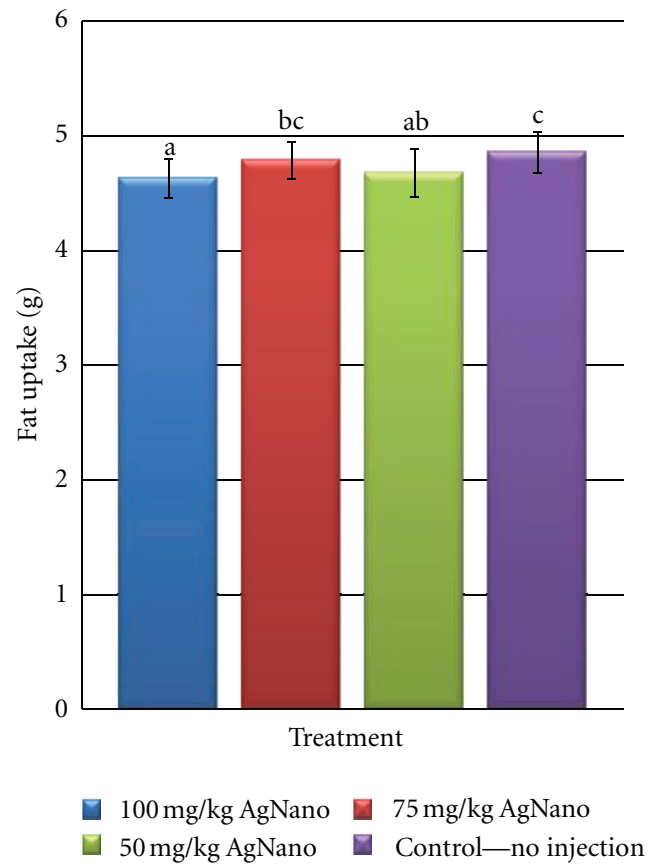

(c)

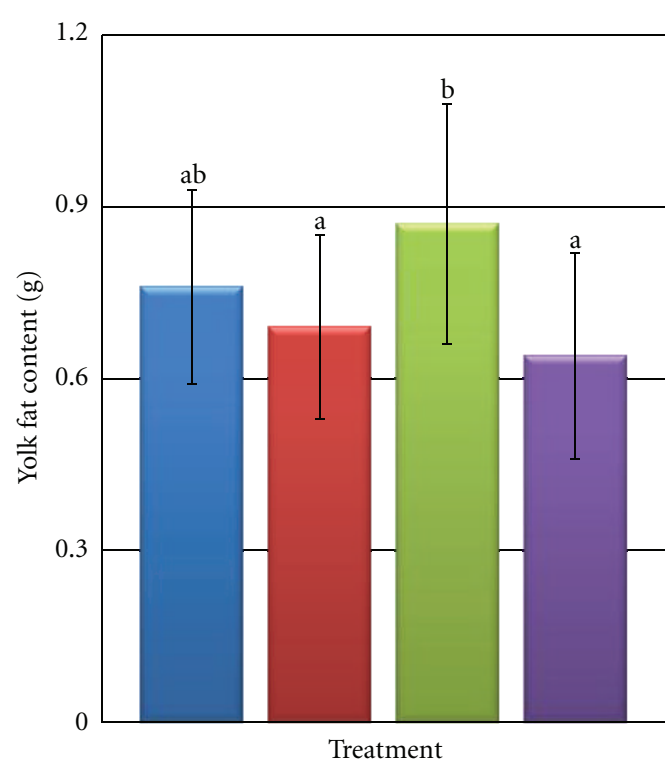

(b)

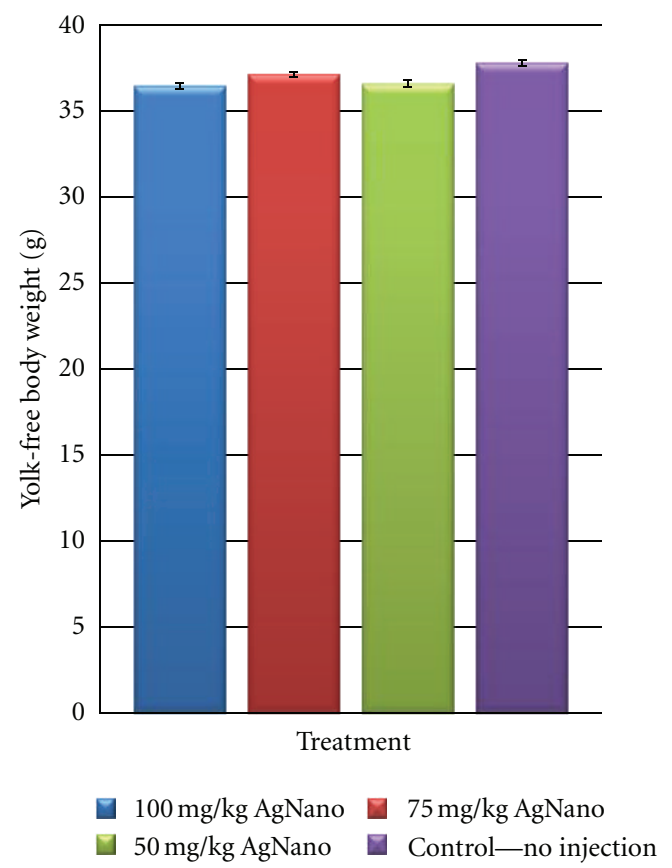

(d)

Figure 1: Comparison of (a) yolk sac weight (YS), (b) yolk fat content (YF), (c) fat uptake (FU), and (d) yolk-free body weight (YFBW) of hatchlings in ovo injected with different concentrations of AgNano $(50,75$, and $100 \mathrm{mg} / \mathrm{kg}$ ) and the control (no injection) at $24 \mathrm{~h}$ after hatching. Mean values and standard errors of 4 treatments, each containing 10 chicks. ${ }^{\mathrm{a}, \mathrm{b}, \mathrm{c}}$ Significant difference $(P<0.05)$ between treatments.

with $75 \mathrm{mg}$ AgNano/kg, which suggested that the pattern of oxidation did not respond linearly to the increase in $\mathrm{AgNano}$ concentration. The reason for this response is unknown, but perhaps the rates of $\mathrm{O}_{2}$ consumption could explain this pattern of fat oxidation. $\mathrm{O}_{2}$ supply is essential for the $\beta$-oxidation of fatty acids from the yolk and effective retrieval of lipids during incubation, as pointed out in several reviews [1-4] and demonstrated in previous study that the rate of $\mathrm{O}_{2}$ consumption influences the amount of yolk fat used [14]. Further, $\mathrm{O}_{2}$ consumption and $\mathrm{FU}$ are positively correlated as documented in several studies $[9,11]$, which showed that a lower $\mathrm{O}_{2}$ consumption rate and higher yolk weight are associated with less fat oxidation. In our study, this positive relationship between $\mathrm{O}_{2}$ consumption 


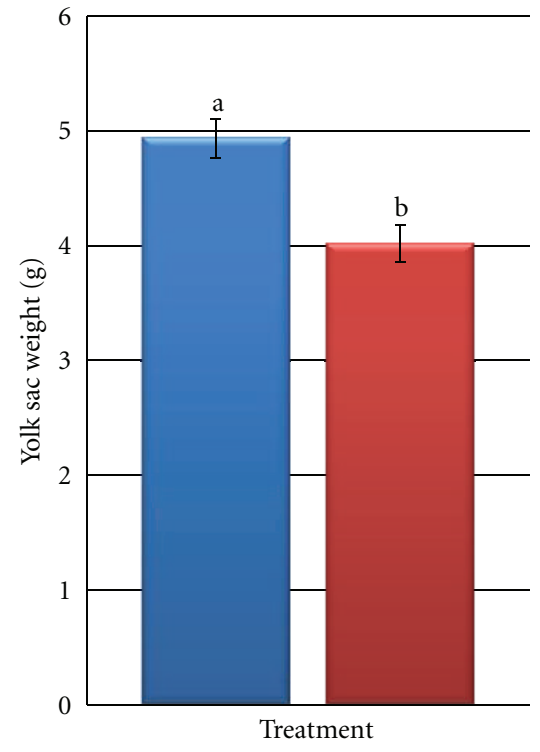

(a)

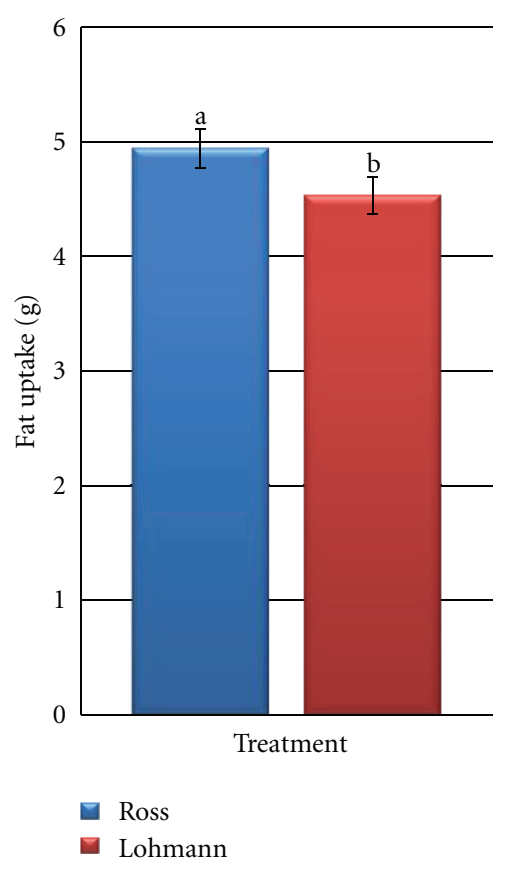

(c)

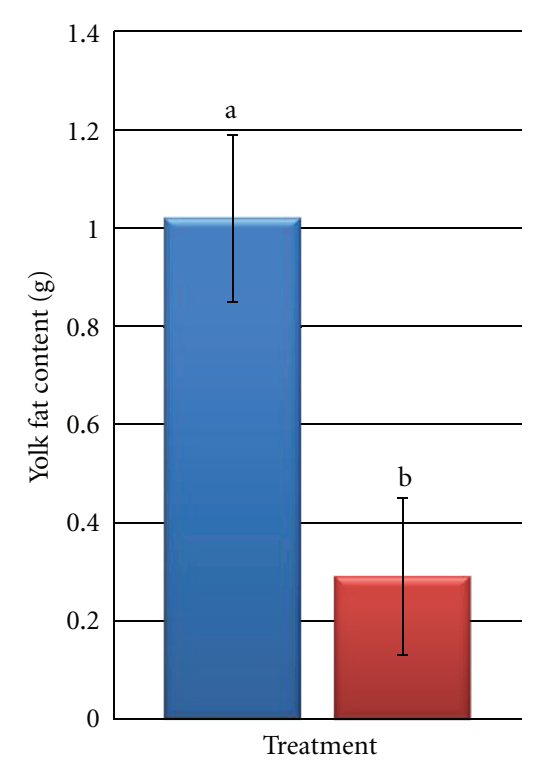

(b)

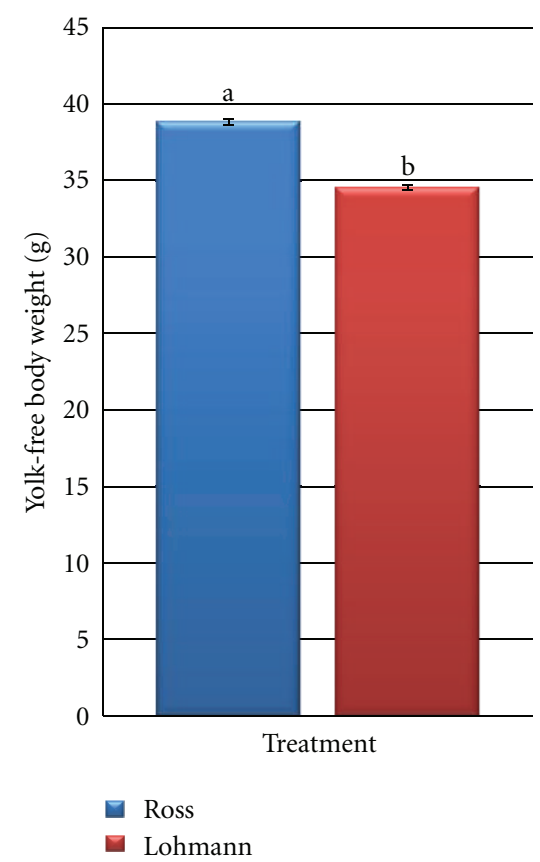

(d)

FIGURE 2: Comparison of (a) yolk sac weight (YS), (b) yolk fat content (YF), (c) fat uptake (FU), and (d) yolk-free body weight (YFBW) of Ross (broiler-type) and Lohmann (layer-type) hatchlings in ovo injected with different concentrations of AgNano (50, 75, and 100 mg/kg) and the control (no injection) at $24 \mathrm{~h}$ after hatching. Mean values and standard errors of 4 treatments, each containing 10 chicks. ${ }^{\mathrm{a}, \mathrm{b}}$ Significant difference $(P<0.05)$ between treatments.

and FU was documented; hatchlings treated with 50 and $100 \mathrm{mg}$ AgNano/kg exhibited lower rates of $\mathrm{O}_{2}$ consumption which explains the lower FU.

Several studies have demonstrated that at hatching, the weights of the residual YS, YF, and FU are higher in broiler compared to layer hatchlings because of the higher metabolic rate in the former, which favours the oxidation of fat and explains the higher rates of fat consumption $[8,9,15]$.
In the present study, similar results were documented in broiler hatchlings for the same parameters. Apart from the difference in metabolic rates, we also attributed the increase in these parameters to the bigger size of eggs and yolks in broilers that contain more fat and possibly other nutrients, being responsible for the larger weight of the YS and higher YF content in broiler hatchlings [14, $16]$. 
No significant interaction effect between treatments and breeder strain was noted on YS, YF, and FU of hatchlings. This can be explained by the lack of an interaction effect on the metabolic rate exhibited by both breeder strains in response to AgNano treatments.

4.2. Metabolic Rate. In comparison with the control (no injection) group, a negative effect on the metabolic rate was recorded in hatchlings injected with 50 and $100 \mathrm{mg}$ AgNano/kg. This finding is contrary to our previous work [7] and the reason for this is unknown. It is probable that the AgNano concentration of $50 \mathrm{mg} / \mathrm{kg}$ is too low and $100 \mathrm{mg} \mathrm{AgNano} / \mathrm{kg}$ is too high to increase the metabolic rate. It is apparent from the present results that the metabolic rate of hatchlings treated with $75 \mathrm{mg} \mathrm{AgNano} / \mathrm{kg}$ was higher than with 50 and $100 \mathrm{mg}$ AgNano/kg but comparable with the control (no injection) group, suggesting that the optimum concentration that would increase the metabolic rate is within the range of $50-100 \mathrm{mg} / \mathrm{kg}$, but this remains to be elucidated.

In agreement with other studies [7, 9, 17-19], our work documented that the metabolic rate of broiler embryos was higher compared with layer embryos.

The lack of a significant interaction effect between the treatment and breeder strain on the metabolic rate was not in complete agreement with our previous study. In conformity with previous experiments $[7,20]$, the metabolic rate of broiler embryos was not affected by AgNano treatment, probably because of genetically programmed maxima. However, the lack of an effect in layers is a contrasting result, as we have previously recorded a significant increase in $\mathrm{O}_{2}$ consumption in layer embryos injected with $50 \mathrm{mg} \mathrm{AgNano} / \mathrm{kg}$. The difference between studies could be caused by differences in egg shell conductance and porosity between the breeder flock used, possibly as an effect of age. The metabolic rate of layer embryos from the older breeder flock used in the previous study was 30\% lower than in embryos produced by the peak breeder flock used in the current work $\left(9 \mathrm{~mL} * \mathrm{~h}^{-1}\right.$ versus $13 \mathrm{~mL} * \mathrm{~h}^{-1}$ ) [7]. It has previously been reported that egg shell conductance and porosity decrease as a breeder flock ages [21]. If this is the case, it can be speculated that the decrease in shell porosity possibly reduced the $\mathrm{O}_{2}$ diffusion capacity of the shell pore system and the resultant hypoxia limited metabolism in the old breeder flock [5]. The findings of our studies may suggest that the effect of AgNano on metabolic rate is influenced not only by strain, but also by the rate of $\mathrm{O}_{2}$ consumption of the embryo. It seems that AgNano exert most of their effect on the metabolic rate of layer embryos with less porous shells and a limited supply of $\mathrm{O}_{2}$. These assumptions, however, need to be confirmed in further research since we did not assess shell conductance and porosity in either of the studies conducted.

4.3. Hatchling Development. In the current study, the YFBW and relative organ weights of chicks were used as an indicator of hatchling development. The YFBW was higher for broiler than for layer hatchlings, which is in agreement with the documented higher BW and faster development in broiler
TABLE 1: Total oxygen consumption $\left(\mathrm{O}_{2}\right)$, carbon dioxide production $\left(\mathrm{CO}_{2}\right)$, and heat production (HP) of layer (LohmannLo) and broiler (Ross-Ro) hatchlings in ovo injected with different concentrations of AgNano (50, 75, and $100 \mathrm{mg} / \mathrm{kg}$ ) and the control (no-injection, C) measured at embryonic days 13 to $19^{1}$.

\begin{tabular}{lccc}
\hline & $\begin{array}{c}\mathrm{O}_{2} \\
\mathrm{~mL} * \mathrm{~h}^{-1}\end{array}$ & $\begin{array}{c}\mathrm{CO}_{2} \\
\mathrm{~mL} * \mathrm{~h}^{-1}\end{array}$ & $\begin{array}{c}\mathrm{HP} \\
\mathrm{J} * \mathrm{~h}^{-1}\end{array}$ \\
\hline Treatment & & & \\
100 & $13.2^{\mathrm{a}}$ & $8.4^{\mathrm{a}}$ & $255^{\mathrm{a}}$ \\
75 & $13.7^{\mathrm{b}}$ & $8.9^{\mathrm{b}}$ & $267^{\mathrm{b}}$ \\
50 & $13.2^{\mathrm{a}}$ & $8.3^{\mathrm{a}}$ & $255^{\mathrm{a}}$ \\
$\mathrm{C}$ & $14.3^{\mathrm{b}}$ & $9.3^{\mathrm{b}}$ & $279^{\mathrm{b}}$ \\
Breeder strain & & & \\
Lohmann & $12.7^{\mathrm{a}}$ & $8.0^{\mathrm{a}}$ & $245^{\mathrm{a}}$ \\
Ross & $14.6^{\mathrm{b}}$ & $9.6^{\mathrm{b}}$ & $284^{\mathrm{b}}$ \\
SE ${ }^{2}$ & 0.121 & 0.124 & 2.45 \\
$P$ value & & & \\
Treatment & 0.001 & $<0.0001$ & $<0.0001$ \\
Breeder strain & $<0.0001$ & $<0.0001$ & $<0.0001$ \\
Treatment $\times$ strain & 0.64 & 0.06 & 0.06 \\
\hline
\end{tabular}

Within columns: means with different superscripts differed significantly $(P<0.05)$.

${ }^{1}$ Mean values of 4 treatments, each containing 24 embryos per breeder strain.

${ }^{2}$ Pooled standard error.

versus layer chicken embryos reported previously [7, 9, 17, 22]. The difference in hatchling development in the present study could be associated primarily with differences in genetic background between breeder strains [19], the pattern of fat utilisation $[8,9]$, and egg size [16].

The present results also demonstrate a difference in the relative intestine weight between breeder strains. We recorded a higher relative weight of the intestine in broiler compared to layer hatchlings, which may indicate more advanced maturation of the intestine in broiler hatchlings [22]. A probable reason could be that the broiler chickens have a short production period and it is important that the intestine reaches its functional capacity as early as possible to enhance digestion of nutrients and growth $[3,15]$.

Hatchling development was not affected by the AgNano concentration. This lack of treatment effect is consistent with findings in quail, pigs, and chickens and supports the conclusion that AgNano do not affect growth [7, 20, 23-25]. Interestingly, the difference in fat uptake between treatments was not reflected in hatchling development. The development of hatchlings treated with 50 and $100 \mathrm{mg} \mathrm{AgNano} / \mathrm{kg}$ was maintained with minimal consumption of YF, which may suggest that other nutrients were utilized [10], or it could be that the difference in FU was too small to elicit an effect on growth. It is also probable that the period of observation was too short $(24 \mathrm{~h})$ for the difference to be determined. It has previously been shown that the effect of dietary fat on the growth of neonatal broiler chickens is greatest at 10 days of age [26]. 


\section{Conclusion}

The results demonstrate that AgNano at 50 and $100 \mathrm{mg} / \mathrm{kg}$ affected the metabolic rate and fat uptake; however, it did not influence the development of hatchlings. In ovo injection of AgNano at 50 and $100 \mathrm{mg} / \mathrm{kg}$ reduces the need to use yolk fat as an energy source, and it can be speculated that the remaining fat in the residual YS can be a potent source of posthatching nutritional reserves for hatchlings. However, further investigation is necessary to establish its potential.

\section{Acknowledgment}

This work was supported by the Danish Agency for Science Technology and Innovation (Grant no. 2106-08-0025).

\section{References}

[1] R. C. Noble and M. Cocchi, "Lipid metabolism and the neonatal chicken," Progress in Lipid Research, vol. 29, no. 2, pp. 107-140, 1990.

[2] B. K. Speake, A. M. B. Murray, and R. C. Noble, "Transport and transformations of yolk lipids during development of the avian embryo," Progress in Lipid Research, vol. 37, no. 1, pp. 1-32, 1998.

[3] J. E. De Oliveira, Z. Uni, and P. R. Ferket, "Important metabolic pathways in poultry embryos prior to hatch," World's Poultry Science Journal, vol. 64, no. 4, pp. 488-499, 2008.

[4] E. T. Moran Jr., "Nutrition of the developing embryo and hatchling," Poultry Science, vol. 86, no. 5, pp. 1043-1049, 2007.

[5] M. K. Stock and J. Metcalfe, "Stimulation of growth of the chick embryo by acute hyperoxia," Respiration Physiology, vol. 58, no. 3, pp. 351-358, 1984.

[6] Z. Uni and R. P. Ferket, "Methods for early nutrition and their potential," World's Poultry Science Journal, vol. 60, no. 1, pp. 101-111, 2004.

[7] L. Pineda, E. Sawosz, A. Hotowy et al., "Effect of nanoparticles of silver and gold on metabolic rate and development of broiler and layer embryos," Comparative Biochemistry and Physiology A, vol. 161, no. 3, pp. 315-319, 2012.

[8] M. Sato, T. Tachibana, and M. Furuse, "Heat production and lipid metabolism in broiler and layer chickens during embryonic development," Comparative Biochemistry and Physiology A, vol. 143, no. 3, pp. 382-388, 2006.

[9] S. Druyan, "The effects of genetic line (broilers vs. layers) on embryo development," Poultry Science, vol. 89, no. 7, pp. 14571467, 2010.

[10] L. Yadgary, A. Cahaner, O. Kedar, and Z. Uni, "Yolk sac nutrient composition and fat uptake in late-term embryos in eggs from young and old broiler breeder hens," Poultry Science, vol. 89, no. 11, pp. 2441-2452, 2010.

[11] A. Chwalibog, A. H. Tauson, A. Ali, C. Matthiesen, K. Thorhauge, and G. Thorbek, "Gas exchange, heat production and oxidation of fat in chicken embryos from a fast or slow growing line," Comparative Biochemistry and Physiology A, vol. 146, no. 3, pp. 305-309, 2007.

[12] E. Brouwer, "Report of sub-committee on constants and factors," in Energy Metabolism in Farm Animals, EAAP Publication, K. L. Blaxter, Ed., vol. 11, pp. 441-443, Academic Press, New York, NY, USA, 1965.

[13] A. Chwalibog, E. Sawosz, A. Hotowy et al., "Visualization of interaction between inorganic nanoparticles and bacteria or fungi," International Journal of Nanomedicine, vol. 5, no. 1, pp. 1085-1094, 2010.

[14] A. Lourens, R. Molenaar, H. Van Den Brand, M. J. W. Heetkamp, R. Meijerhof, and B. Kemp, "Effect of egg size on heat production and the transition of energy from egg to hatchling," Poultry Science, vol. 85, no. 4, pp. 770-776, 2006.

[15] R. M. Gous, "Nutritional limitations on growth and development in poultry," Livestock Science, vol. 130, no. 1-3, pp. 25$32,2010$.

[16] A. Nangsuay, Y. Ruangpanit, R. Meijerhof, and S. Attamangkune, "Yolk absorption and embryo development of small and large eggs originating from young and old breeder hens," Poultry Science, vol. 90, no. 11, pp. 2648-2655, 2011.

[17] O. Janke, B. Tzschentke, and M. Boerjan, "Comparative investigations of heat production and body temperature in embryos of modern chicken breeds," Avian and Poultry Biology Reviews, vol. 15, no. 3-4, pp. 191-196, 2004.

[18] E. E. O’Dea, G. M. Fasenko, J. J. R. Feddes et al., "Investigating the eggshell conductance and embryonic metabolism of modern and unselected domestic avian genetic strains at two flock ages," Poultry Science, vol. 83, no. 12, pp. 2059-2070, 2004.

[19] L. De Smit, K. Tona, V. Bruggeman et al., "Comparison of three lines of broilers differing in ascites susceptibility or growth rate. 2. Egg weight loss, gas pressures, embryonic heat production, and physiological hormone levels," Poultry Science, vol. 84, no. 9, pp. 1446-1452, 2005.

[20] E. Sawosz, M. Grodzik, M. Zielinska, T. Niemiec, B. Olszanska, and A. Chwalibog, "Nanoparticles of silver do not affect growth, development and DNA oxidative damage in chicken embryos," Archiv für Geflügelkunde, vol. 73, no. 3, pp. 208-213, 2009.

[21] J. A. Hamidu, G. M. Fasenko, J. J. R. Feddes et al., "The effect of broiler breeder genetic strain and parent flock age on eggshell conductance and embryonic metabolism," Poultry Science, vol. 86, no. 11, pp. 2420-2432, 2007.

[22] L. J. F. Van De Ven, A. V. Van Wagenberg, M. Debonne, E. Decuypere, B. Kemp, and H. Van Den Brand, "Hatching system and time effects on broiler physiology and posthatch growth," Poultry Science, vol. 90, no. 6, pp. 1267-1275, 2011.

[23] E. Sawosz and M. Grodzik, "The influence of silver nanoparticles on chicken embryo development and bursa of Fabricius morphology," Journal of Animal and Feed Sciences, vol. 15, supplement 1, pp. 111-114, 2006.

[24] E. Sawosz, M. Binek, M. Grodzik et al., "Influence of hydrocolloidal silver nanoparticles on gastrointestinal microflora and morphology of enterocytes of quails," Archives of Animal Nutrition, vol. 61, no. 6, pp. 444-451, 2007.

[25] M. Fondevila, R. Herrer, M. C. Casallas, L. Abecia, and J. J. Ducha, "Silver nanoparticles as a potential antimicrobial additive for weaned pigs," Animal Feed Science and Technology, vol. 150, no. 3-4, pp. 259-269, 2009.

[26] T. N. Chamblee, J. D. Brake, C. D. Schultz, and J. P. Thaxton, "Yolk sac absorption and initiation of growth in broilers," Poultry science, vol. 71, no. 11, pp. 1811-1816, 1992. 

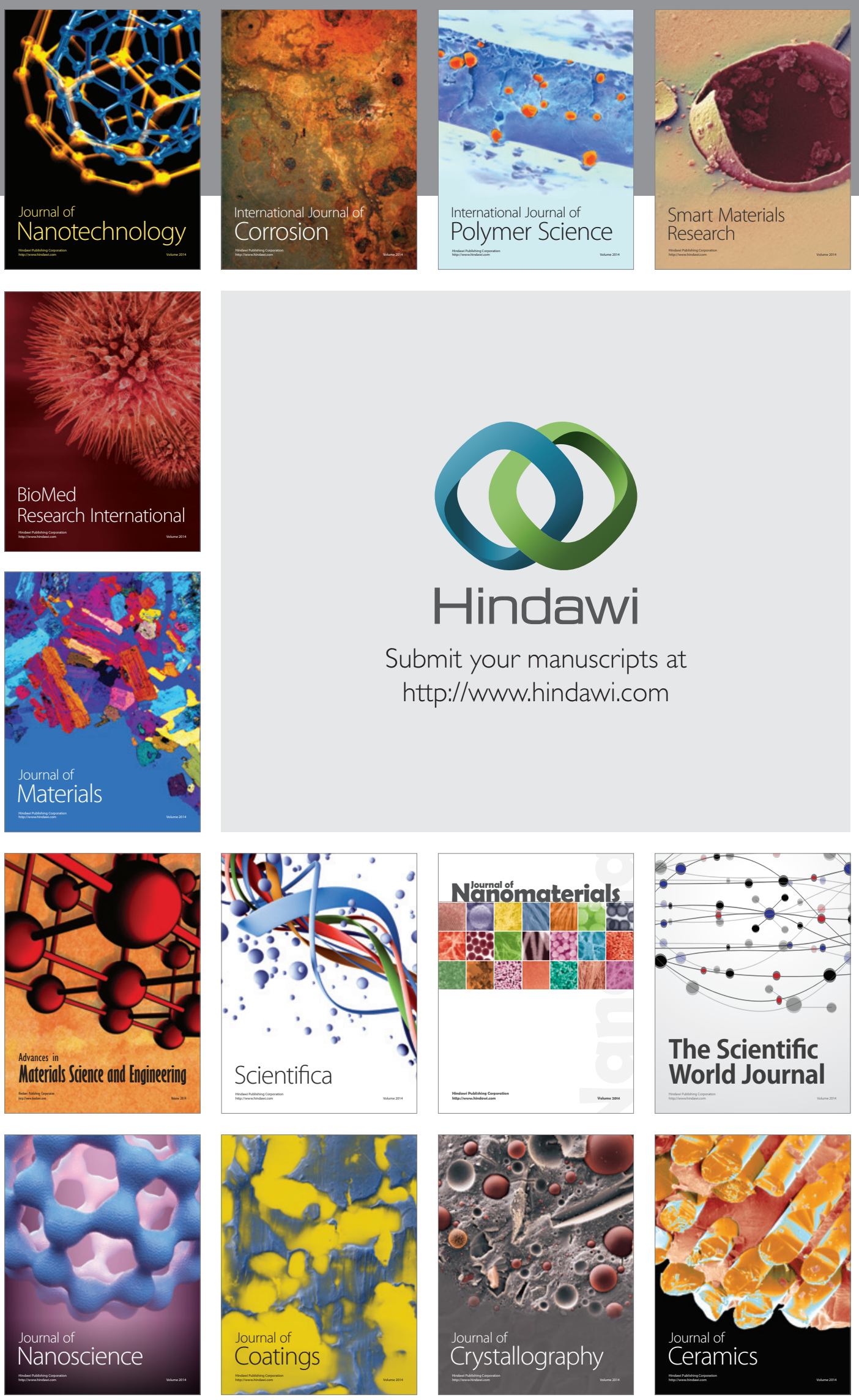

The Scientific World Journal

Submit your manuscripts at

http://www.hindawi.com

\section{World Journal}

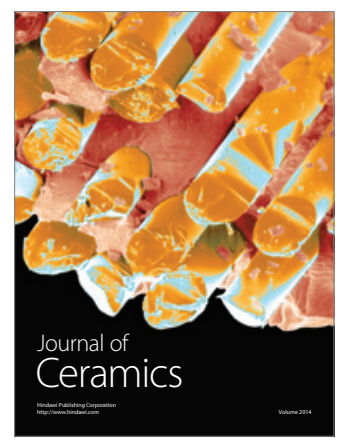

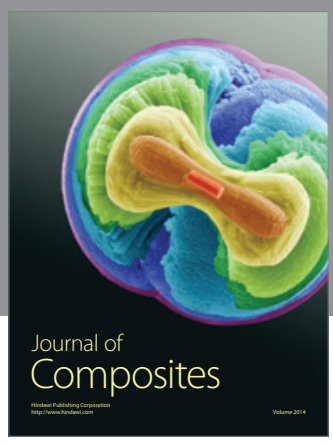
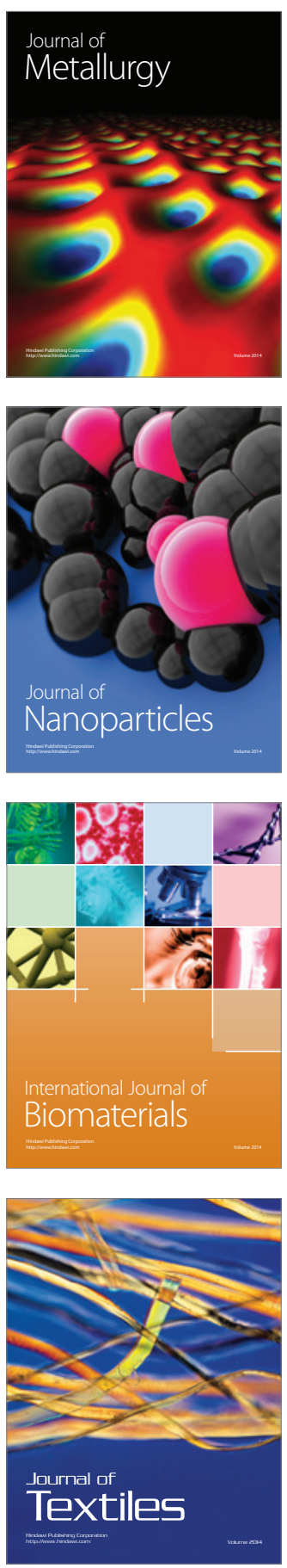